\title{
A experiência no serviço de Consultório de Rua na perspectiva dos profissionais: Contribuiçóes para a atenção ao usuário de álcool e outras drogas ${ }^{1}$
}

\author{
Viviane Cássia Aranda de Souza ${ }^{\mathrm{a}}$, Andrea Ruzzi Pereira ${ }^{\mathrm{b}}$, Daniela Tavares Gontijo ${ }^{\mathrm{c}}$ \\ aniversidade Federal de Pernambuco - UFPE, Recife, PE, Brasil \\ ${ }^{\mathrm{b}}$ Curso de Terapia Ocupacional, Universidade Federal do Triângulo Mineiro - UFTM, Uberaba, MG, Brasil \\ ${ }^{c}$ Curso de Terapia Ocupacional, Universidade Federal de Pernambuco - UFPE, Recife, PE, Brasil
}

\begin{abstract}
Resumo: A assistência a usuários de álcool e outras drogas no Brasil passou por diversas transformações devido a fenômenos históricos, sociais e políticos. Em 2009, o Ministério da Saúde criou o Consultório de Rua, visando à redução de danos à população em situação de rua e em vulnerabilidade ao uso de álcool ou outras drogas. $\mathrm{O}$ objetivo deste estudo foi descrever e analisar a experiência no serviço de Consultório de Rua na perspectiva dos profissionais que compõem a equipe de um município da Região Metropolitana do Recife, PE. Trata-se de um estudo qualitativo, com dados coletados através de entrevistas semiestruturadas com cinco profissionais e submetidos à Análise de Conteúdo Temática. O conteúdo das entrevistas explicitou o caráter dinâmico da realidade vivenciada pelos profissionais e o momento de implantação e consolidação do serviço no município, sendo possível caracterizar os objetivos, clientela, demanda dos usuários, sistematização das ações e dificuldades do/no serviço. Foi possível identificar congruência entre as experiências vivenciadas pelos participantes da pesquisa e o que é preconizado pelo Ministério da Saúde assim como semelhanças com outros serviços descritos na literatura. Além disso, os dados revelaram o desafio vivenciado pelos profissionais cotidianamente, expressos principalmente nas dificuldades relatadas. O estudo trouxe subsídios que podem direcionar a implantação de outras equipes de Consultório de Rua e a formação dos profissionais, inclusive de terapeutas ocupacionais, para atuação nesse campo.
\end{abstract}

Palavras-chave: Vulnerabilidade Social, Drogas de Uso Indevido, Assistência à Saúde Mental, Terapia Ocupacional.

\section{The experience in the service of Street Clinic in the view of professionals: Contributions to the care for users of alcohol and other drugs}

\begin{abstract}
Assistance to users of alcohol and other drugs in Brazil has undergone several transformations owing to historical, social, and political phenomena. In 2009, the Ministry of Health created the 'Street Clinic' in order to reduce harm to the homeless and the population vulnerable to use of alcohol or other drugs. The aim of this study was to describe and analyze the experience at a 'Street Clinic' from the perspective of the professionals who compose the service team in a municipality located in the metropolitan region of Recife, Pernanbuco state. This is a qualitative study with data collected through semi-structured interviews with five professionals and submitted to qualitative analysis. The content of the interviews explained the dynamic character of the reality experienced by professionals and the time of implementation and consolidation of this service in the city, characterizing the objectives, clientele, user demand, and systematization of actions and difficulties in delivering the service. It was possible to identify similarities between the experiences of the research participants and what is recommended by the Ministry of Health, as well as similarities with other services described in the literature. Furthermore, the data revealed the day to day challenges experienced by the professionals expressed mainly in the difficulties reported in the interviews. The study provided a good basis for the implementation of other Street Clinic teams and the training of professionals, including occupational therapists, to work in this field.
\end{abstract}

Keywords: Social Vulnerability, Street Drugs, Mental Health Assistance, Occupational Therapy.

Autor para correspondência: Daniela Tavares Gontijo, Departamento de Terapia Ocupacional, Universidade Federal de Pernambuco, Av. Prof. Moraes Rego, s/n, Cidade Universitária, CEP 50670-901, Recife, PE, Brasil, e-mail: danielatgontijo@gmail.com

Recebido em 23/08/2013; $1^{\text {a }}$ revisão em 17/02/2014; Aceito em 04/05/2014. 


\section{Introdução}

Pensar a atenção a usuários de álcool e outras drogas numa perspectiva que faça frente às questôes mais abrangentes que esse fenômeno coloca em discussão requer que se considere o sujeito para além da sua condição de "usuário de drogas" e se lance o olhar para as demais dimensôes que compóem sua trajetória de vida. São sujeitos em elevada condiçáo de vulnerabilidade social e de saúde uma vez que, além dos danos físicos e psicológicos decorrentes do uso abusivo, existem os danos causados pela condição de ilegalidade ou de marginalidade a que são relegados, expondo-os a violência de diversas formas (OLIVEIRA; NAPPO, 2008).

Desse modo, a atuaçáo junto a esses sujeitos tem sido pensada numa lógica de redes de assistência que articulem diversos atores sociais, como saúde, assistência social, educação, sociedade civil em seus vários setores, de modo a oferecer-lhes uma atenção integral e integrada (BRASIL, 2004).

Nesse sentido, a rede pública de atenção psicossocial, além dos Centros de Atenção Psicossocial Álcool e Outras Drogas (CAPS-ad), ainda tem o apoio das casas de acolhimento transitório, dos hospitais gerais, prontos-socorros e, atualmente e de forma crescente, das equipes de Consultório de Rua (eCR). Essas últimas surgiram na regiấo de Salvador, Bahia, entre 1988 e 1990, inicialmente denominadas "Banco de Rua", e consistiam na observação e aproximação com a população em situação de risco social. Em 1995, visando à redução de danos decorrentes do uso de substâncias psicoativas e a prevenção às doenças sexualmente transmissíveis (DST), o projeto foi retomado com jovens em situação de rua envolvidos com álcool ou outras drogas, denominando-se "Consultório de Rua" (CR) (COUTINHO; SABACK, 2007).

Em 2009, o Ministério da Saúde (MS) propôs o CR como estratégia do Plano Emergencial de Ampliação de Acesso ao Tratamento e Prevençáo em Álcool e outras Drogas no Sistema Único de Saúde - PEAD e, em 2010, o equipamento foi incluído no Plano Integrado de Enfrentamento ao Crack (BRASIL, 2010).

Compreende-se que o CR é uma das portas de entrada para a rede de assistência e saúde, disponibilizando encaminhamentos necessários nas açôes. Devem oferecer cuidados básicos de saúde, orientação, prevenção, assistência e tratamento, de acordo com as particularidades dos sujeitos. Em 2011, por meio da Portaria n. 2.488/11, que aprovou a Política Nacional de Atenção Básica, foi instituído o Consultório na Rua, que propóe a formaçáo de equipes itinerantes que atuam na Atenção Integral à Saúde da população em Situação de Rua, ampliando as possibilidades de intervenção das equipes dos Consultórios de Rua que direcionam sua atenção para o atendimento à Saúde Mental (BRASIL, 2011, 2012a, b).

A eCR adota a redução de danos como estratégia de intervenção, considerando-a a forma mais potente de aproximação à população usuária de droga, permitindo construçáo de vínculos de confiança, estimulando a autoestima e a cidadania do indivíduo (GONÇALVES; BRAITENBACH, 2010; SANTOS; MALHEIRO, 2010; VALÉRIO; MENEZES, 2010; COUTINHO; SABACK, 2007).

Ações de Redução de Danos referem-se a

[...] um conjunto de políticas e práticas cujo objetivo é reduzir os danos associados ao uso de drogas psicoativas em pessoas que não podem ou não querem parar de usar drogas. Por definição, redução de danos foca na prevenção aos danos, ao invés da prevenção do uso de drogas; bem como foca em pessoas que seguem usando drogas (INTERNATIONAL..., 2010).

Surgidas nos anos 1980 na Holanda e no Reino Unido como resposta ao crescente número de infecçôes por HIV entre usuários de drogas injetáveis e introduzidas no Brasil no ano de 1989, na cidade de Santos, São Paulo, as estratégias de redução de danos, adotando um olhar ampliado sobre a questão das drogas, para além do uso em si, têm por objetivo promover a autonomia dos sujeitos, entendendo-os como cidadáos de direitos, ativos no processo de enfrentamento da problemática em que estão inseridos. Buscam valorizar os saberes dos atores envolvidos, mais do que apenas o saber técnico, e a construção conjunta de soluções para cada usuário, aceitando, portanto, diversos contratos que não só a abstinência da droga (SANTOS; MALHEIRO, 2010).

Segundo o Ministério da Saúde, em 2013, 52 projetos de Consultório na Rua/de Rua estáo desenvolvendo-se no Brasil, compostos por equipes interdisciplinares de profissionais da saúde mental, da atenção básica e da assistência social. Pernambuco tem quatro municípios com equipes de Consultório de Rua (eCR) , sendo esses Recife, Cabo de Santo Agostinho, Paulista e Jaboatáo dos Guararapes e dois municípios com equipes de Consultório na Rua, que são Camaragibe e Olinda (BRASIL, 2013; PERNAMBUCO, 2012).

Considerando esses aspectos, o presente estudo teve como objetivo descrever e analisar a experiência 
no serviço de CR na perspectiva dos profissionais que compóem a equipe de um município da Regiáo Metropolitana do Recife, PE.

Espera-se que esta pesquisa traga subsídios que possam direcionar a implantação de outras eCR e a formação dos profissionais, inclusive de terapeutas ocupacionais, para atuação junto à população em uso de álcool e outras drogas.

\section{Procedimentos metodológicos}

Estudo com abordagem qualitativa de caráter exploratório e descritivo (MINAYO, 2008). A pesquisa foi realizada com uma eCR vinculada à um CAPSad localizado em um município da Região Metropolitana do Recife, PE, que iniciou as suas atividades em abril de 2011.

A equipe era composta por seis profissionais, com experiência superior a seis meses no serviço, sendo que cinco deles participaram da pesquisa. Um profissional não foi entrevistado em decorrência de seu afastamento do serviço durante a coleta de dados.

Os dados foram coletados por meio de uma entrevista semiestruturada, com utilização de um roteiro cuja adequação aos propósitos do estudo foi avaliada por meio da realizaçáo de duas entrevistas piloto com estagiárias do serviço. O roteiro de entrevistas continha questóes relacionados aos objetivos, à clientela, à demanda do público atendido, às açóes realizadas e às dificuldades no cotidiano do trabalho.

As entrevistas foram realizadas no CAPSad, no período de janeiro a março de 2013 , em uma sala que garantiu a privacidade e em horário combinado previamente com os entrevistados.

Gravadas em equipamento de áudio, as entrevistas foram transcritas na íntegra e os dados submetidos à análise de conteúdo temática, de acordo com a proposta de Gomes (2008).

A coleta de dados foi condicionada à compreensão e assinatura do Termo de Consentimento Livre e Esclarecido pelos participantes, sendo que eles mesmos escolheram os codinomes pelos quais são identificados neste estudo.

\section{Resultados e discussão}

\subsection{Caracterização dos participantes}

Participaram da pesquisa cinco profissionais da eCR (psicólogo, terapeuta ocupacional, enfermeira, técnica de enfermagem e um condutor). A idade dos participantes variou de 37 a 55 anos (média de 46 anos), sendo dois homens e três mulheres. $\mathrm{O}$ tempo de experiência no CR foi de um ano e seis meses, em média.

O conteúdo das entrevistas explicitou o caráter dinâmico da realidade vivenciada pelos sujeitos em virtude do momento de implantação e consolidação do serviço no município, sendo esse alocado nas seguintes categorias que refletem o cotidiano da eCR: objetivos, clientela, demanda dos usuários, sistematização das açóes e dificuldades do/no serviço.

\subsection{Objetivos do CR}

O primeiro aspecto abordado com os entrevistados referiu-se aos objetivos que eles atribuem ao $\mathrm{CR}$. Nesse aspecto, foi citado como objetivo a orientação a toda população, com ênfase nos indivíduos usuários de álcool e outras drogas e/ou em situação de rua. Essas orientaçôes referem-se principalmente à existência de instituiçóes nas quais pode-se buscar atendimento nessas problemáticas.

\section{O objetivo do CR é levar à população, é alertar a população, orientar a população acerca do uso de drogas e os seus males, alertar também quanto a orientar no sentido de que existem instituiçôes como o CAPS, que é Centro de Atenção Psicossocial (Alice).}

Outro objetivo citado foi a oferta e articulação de serviços da área da saúde, educação, justiça e assistência social. Referiu-se que a eCR trabalha em três eixos (prevenção, intervenção e encaminhamento), compondo um equipamento que articula as redes de Saúde Mental e de assistência social.

\begin{abstract}
Na hora que a gente vai pra rua ofertar serviços a usuários que estão em situação de rua, se quiserem, óbvio, né, tem que ter o desejo, a gente tem claro todos os equipamentos intersetoriais, tanto da saúde, da educação, da justiça, enfim, principalmente da assistência. Então é uma grande linha que amarra a rede do [município] (Magia).
\end{abstract}

O monitoramento das áreas de vulnerabilidade social também foi citado como objetivo do CR. Além disso, na perspectiva dos sujeitos, o equipamento tem como meta "resgatar" pessoas em vulnerabilidade de álcool e outras drogas, possibilitando que saiam da margem e se reintegrem à sociedade.

Tentar resgatar aquelas pessoas que estão em vulnerabilidade de álcool e outras drogas, né. É tentar resgatar para [...] sair da margem $d a$ sociedade em que eles vivem, né, a maioria vive envolvido em álcool e drogas (Marcelo). 
Destacou-se que o CR náo tem o objetivo de higienizar o território, de tirar as pessoas da rua. Não obriga ninguém a aderir ao tratamento, considerando o desejo do usuário. Utilizando o vínculo formado, a equipe mostra alternativas de tratamento ou reinserção social, como a participação em grupos de apoio e orientação nas comunidades, conforme decisão do usuário.

Intervenção com atendimento, com acompanhamento é quando há desejo do usuário. Se ele não deseja, a gente náo vai higienizar $o$ território, a gente não vai tirar da rua, não vai puxar, jogar dentro do carro de jeito nenhum. A gente vai usar o vinculo, mostrando a necessidade, mas respeitando o direito dele enquanto cidadão de até dizer não, "eu não quero, eu não vou" (Magia).

Os objetivos citados pelos entrevistados para o CR vão ao encontro do que é preconizado pelo Ministério da Saúde (BRASIL, 2010), que destaca que esse serviço deve oferecer aos usuários de substâncias psicoativas em situação de maior vulnerabilidade cuidados básicos de saúde, realizando atendimentos em seu local de permanência e fazendo encaminhamentos para a rede de saúde e assistência social das demandas mais complexas. Dessa forma, o equipamento serve como ponte para essa população, possibilitando sua inserção na rede de cuidado e proteção.

Os objetivos citados pelos profissionais e preconizados pelo Ministério da Saúde (BRASIL, 2010) refletem a postura de acolhimento e de cuidado humanizado que deve caracterizar o CR. Durante o acolhimento, o profissional deve realizar escuta sensível e dar assistência ao usuário, ajudando-o a refletir e encontrar resolubilidade do seu problema, de acordo com seus desejos (JORGE; CORRADIWEBSTER, 2012; MORAIS et al., 2010).

\subsection{Clientela do CR}

No discurso dos sujeitos foi possível identificar características do perfil da clientela atendida pela equipe, inclusive idade e gênero.

Sobre o perfil da clientela, todos os profissionais afirmaram que essa é composta principalmente por pessoas que estão em situação de rua, em vulnerabilidade.

A maior necessidade são aquelas pessoas que estão bem fragilizados, que não têm moradia, que necessitam de um bom atendimento, que estão ameaçadas, que vivem na rua, que moram na rua e que não têm família [...] pra abrigar, nem dar uma boa moradia, um bom sustento (Mariane).
O uso de álcool e outras drogas pela clientela do CR foi destacado pela maioria dos entrevistados, sendo apontada também a associação dessa situação com transtornos mentais. Foi referido que o $\mathrm{CR}$ não tem clientela específica, envolvendo toda a população e não somente quem está em vulnerabilidade.
A clientela do CR não quer dizer que ele tenha uma clientela, porque ele náo tem uma clientela especifica. Ele envolve toda a população. Porque você pode ter pessoas usuárias de drogas, pode ter pessoas usuárias de álcool, pode ter pessoas com problemas mentais e você pode até ter pessoas com conflitos internos (Alice).

Com relação à idade, relatou-se que as açóes da equipe são destinadas a qualquer faixa etária. No entanto, no cotidiano do serviço, observa-se que a faixa etária varia de acordo com a região da cidade que está sendo atendida, sendo destacada a presença de adolescentes entre 14 e 18 anos.

Com relação ao gênero, os profissionais relataram não haver restrições, sendo que alguns referem que $o$ atendimento é realizado independentemente da orientação sexual e da identidade de gênero das pessoas.

tem pros dois sexos e, inclusive, atualmente tem muito, muitas pessoas que são homoafetivas, né, e tem muitos homens que se transvestem de mulher, né (Sarará).

Os dados obtidos neste estudo são semelhantes aos encontrados na experiência pioneira do CR de Salvador e às características do público apontado pelo MS (BRASIL, 2010) para o serviço. Na experiência de Salvador, o CR propunha dar atenção à saúde dos que vivem em situação de rua, expostos ao uso de substâncias psicoativas, sobretudo crianças e adolescentes. No entanto, também existe uma demanda da população adulta que habita esses mesmos locais (NERY FILHO; VALÉRIO; MONTEIRO, 2011; SANTANA, 2010).

\subsection{Demanda dos usuários nas ações do CR}

Um terceiro aspecto abordado com os entrevistados foi a demanda apresentada pelos usuários nas açóes desenvolvidas pela eCR. A necessidade de informação e orientação com relação aos órgãos que podem atendê-los e solucionar seus problemas foi destacada por uma profissional.

A necessidade do público, o que en percebo é que eles têm, assim, uma carência de orientação. Eles desconhecem muitas vezes quais são as entidades que podem levar a eles uma solução para o problema deles (Alice). 
Um entrevistado lembra que algumas pessoas náo conseguem realizar o tratamento no CAPSad devido a dificuldades financeiras, fazendo com que a equipe articule com o serviço de assistência social a obtenção de subsídios financeiros que possibilitem o transporte delas.

A dificuldade de acesso à saúde foi identificada como sendo uma queixa recorrente dos usuários, sendo solicitado auxílio para a marcação de atendimentos. Além disso, existe a demanda pela obtenção de documentos pessoais.

[...] ai a demanda do pessoal é mais saúde e assistência mesmo. Assim, a gente, eles se queixam muito de pedir pela saúde, né. Assim, pra marcar pra ir pros locais, né (Sarará).

De acordo com a experiência da eCR de uma cidade na Regiāo Metropolitana de Salvador, algumas vezes as demandas dos usuários ultrapassam os objetivos do equipamento. Nesses casos, essa equipe dá orientaçóes, esclarece seus objetivos e realiza os encaminhamentos necessários (NERY FILHO; VALÉRIO; MONTEIRO, 2011).

Dessa forma, é importante que a eCR esteja ciente de seus objetivos, a fim de cumprir as demandas dos usuários do CR de maneira satisfatória e dentro da realidade do serviço, seja com orientaçóes, seja com encaminhamentos interinstitucionais.

\subsection{Sistematização das ações da eCR}

Também se discutiu com os profissionais sobre a sistematização das açóes da eCR no cotidiano. De acordo com os entrevistados, realizam-se reunióes internas de planejamento antes de se sair para cada açáo, nelas se define o que será feito, a área de ação e as ferramentas que serão utilizadas. Nesse momento, cada profissional relata se está preparado para participar das atividades do dia. Após a açấo, a equipe se reúne para observar erros e acertos.

Sempre antes de a gente ir pra rua a gente faz um planejamento, né, a gente planeja como é que vai ser a rua, qual é a área, quais são as ferramentas que a gente vai levar. A gente sempre tem umas reuniōes nas quais a equipe se senta, inclusive até pra falar como cada profissional tá se sentindo, que é importante você ir pra rua carregando essa alegria, né, quando a gente tá meio baqueado a rua fica mais difícil, não fica tão fácil (Sarará).

Além disso, executam-se também planejamentos em médio prazo, em reuniōes internas, geralmente no fim do mês, nas quais faz-se o relatório do mês e o planejamento das atividades do mês seguinte.
Nessas reunióes são utilizadas informaçóes fornecidas pela Secretaria de Saúde acerca das áreas de risco e, em seguida, a equipe organiza um mapa com uma ordem de visitação.

O Guia do Projeto CR e o MS mencionam que o objetivo das reunióes é planejar as atividades do dia - embora elas tenham que se flexibilizar, devido à imprevisibilidade da rua - ou, ainda, discutir sobre as açóes passadas, a fim de saber o que precisa ser mudado (NERY FILHO; VALÉRIO; MONTEIRO, 2011; BRASIL, 2010).

A maioria dos entrevistados relatou ter momentos semanais de estudo em grupo sobre temas relativos à área de atuação em questão.

Geralmente, a equipe se reúne, né, em reuniöes, $e$ a coordenadora faz, assim, distribui determinados assuntos para que as pessoas da equipe possam estudar e possam debater depois, tirando algumas dúvidas (Alice).

A experiência do CR de Salvador apontou que é necessário integrar os saberes dos componentes da equipe. Por isso, a formação da equipe deve ser permanente, por meio de estudos dirigidos, discussóes de casos e supervisão das atividades realizadas, assim como acontece com a eCR da Região Metropolitana do Recife, PE. Nessa perspectiva ocorrem novas trocas de conhecimentos, surgem novos olhares de diferentes níveis de intervenção, tendo a participação de toda a equipe, contribuindo com o objetivo do CR (NERY FILHO; VALÉRIO; MONTEIRO, 2011).

Atender de maneira integral e efetiva aos sujeitos em uso de drogas, dentro da perspectiva do trabalho proposto pelo CR, requer que se atente para a formação de seus agentes num sentido ampliado, agregando a essa formação não somente os saberes técnicos mas também os saberes multivariados desses agentes e de seus clientes, na construção de um saber coletivo que permita um olhar mais compreensivo e os leve considerar a questão das drogas para além do caráter repressor.

Após o planejamento das açóes inicia-se a observação do território, na qual se faz o monitoramento e o mapeamento da regiáo, para conhecê-la.

Primeiro a gente vai ver o território. Conhecer, mapear o território. A gente vai várias vezes ali, dá uma olhada, desce, como um transeunte normal, observa, vê o que é que tem de bares, o que é que tem de pontos mais escuros, mais sinistros, e ai a gente já pensa no local onde ficar (Magia).

A etapa inicial, que é denominada pelos entrevistados como etapa de observação, caracteriza-se 
como um mapeamento da cidade, realizado também pela eCR de Salvador, identificando locais com maior presença de jovens em situação de vulnerabilidade social e em uso de drogas (BRASIL, 2010).

Após mapear o território iniciam-se a aproximação e a abordagem ao usuário, sendo explicitados pelos entrevistados as ferramentas e/ou instrumentos utilizados, além das estratégias.

A abordagem ao usuário pode iniciar-se com a estratégia denominada "paquera pedagógica”, na qual o profissional fica parado com o instrumento musical até alguém do grupo ter interesse e aproximar-se. Segundo a maioria dos profissionais, a equipe utiliza a música, o teatro e a capoeira durante a aproximação, por terem linguagem universal e aproximarem mais as pessoas.

[...] a gente usa as ferramentas que nos aproximam mais, né. Num é que aproxime mais, é que, assim, a musicalidade, o instrumento, ele tem uma linguagem que é universal (Sarará).

O instrumento musical é uma ferramenta importante para favorecer o encontro entre os profissionais e os usuários em situação de rua. Contudo, deve servir de apoio e não como condição para esse encontro. Os CR da Região Metropolitana de Salvador, BA, de forma semelhante ao da Regiāo Metropolitana do Recife, PE, utilizam os instrumentos musicais e também consideram a música uma linguagem universal, principalmente quando ela relaciona-se com a identidade cultural da população local. Embora o público alvo possa ver essas atividades como brincadeiras, geralmente elas têm a funçáo de criar leveza para discussáo de temas tidos como tabu, além de promoverem a aproximação (NERY FILHO; VALÉRIO; MONTEIRO, 2011).

Visto que a eCR se utiliza de atividades na mediação da sua intervenção, o terapeuta ocupacional - que segundo Barros (2010, p. 65) utiliza como recurso a atividade, tendo domínio dessa e vendo nela um "[...] espaço para criar, recriar e reproduzir um mundo humano, cujo processo envolve simbolismo, intenções, desejos e necessidades" - pode trazer contribuiçôes relevantes para potencializar as açốes do CR.

Durante a abordagem a equipe entrega panfletos e realiza orientaçóes sobre o CR e os outros equipamentos da rede de saúde disponíveis para tratamento de álcool e outras drogas no município. Além disso, a eCR entrega insumos (preservativos), que servem tanto para atrair a atenção das pessoas como para a prevenção de DST.
Primeiro a gente tem um, como se diz, um chamariz, que é distribuir camisinhas, né. Que é como a gente consegue chegar até eles. Que é o modo de chegar a eles, né, assim de início a gente tem de trazer algo pra oferecer, né? Vai distribuindo camisinhas e ai a gente panfleteia e fala do serviço que o município oferece em relação ao tratamento (Marcelo).

A eCR aproxima-se das pessoas dialogando sobre o tratamento, os consequências do uso abusivo da droga. A equipe não invade o território de tráfico, frequentando somente locais públicos como escolas, praças, feiras e bares, garantindo sua segurança, como observa-se no trecho abaixo.

a gente se aproxima deles com os folders né? $E$ o nosso meio de nos aproximar mostrando nosso serviço. Até porque no nosso CR a gente não vai em boca de fumo, a gente não vai em lugares, a gente não invade o território deles (Mariane).

Segundo o Ministério da Saúde (BRASIL, 2010), existe uma estratégia de aproximação da eCR denominada como abertura de campo, que também foi referida pelos entrevistados, na qual os profissionais identificam as lideranças do grupo ou comunidade e pedem seu apoio para que a equipe se instale no território, não sendo dessa forma invasiva. $\mathrm{O}$ consentimento das lideranças torna-se um fator positivo para a receptividade do trabalho pela comunidade.

A equipe desenvolve açôes de redução de danos, divulgando os serviços de tratamento, distribuindo panfletos e copos para evitar a transmissão de doenças como tuberculose, além de preservativos e gel lubrificante para prevenção das DST, como foi citado anteriormente. Também foi feita referência à realização de ações de atendimento básico em saúde, principalmente da enfermagem, como verificação de sinais vitais, de pressão arterial, HGT (teste de glicemia) e realização de curativos.

Outro aspecto abordado pelos profissionais do $\mathrm{CR}$ foi a realização de encaminhamentos. $\mathrm{O}$ ato de encaminhar, para uma das profissionais, não é somente "dar o papel" mas também acompanhar o processo junto aos serviços de saúde, assistência social, educação, entre outros setores da rede.

E aí nesse momento a gente encaminha e aí acontece o encaminhamento. A gente procura não só dar o papel, mas acompanhar (Magia).

Os encaminhamentos para a saúde são destinados principalmente às unidades básicas, leitos de hospitais para desintoxicação, policlínicas, CAPS, CAPSad, CAPSadi e residências terapêuticas. Já 
os para a assistência social são geralmente devidos a demandas por documentos ou solicitação de subsídios financeiros que possibilitem o transporte do usuário para o serviço de saúde. Nesses casos, as possibilidades de encaminhamento são o Centro de Referência de Assistência Social (CRAS) e o Centro de Referência Especializado de Assistência Social (CREAS).

Os profissionais referem também como alternativas o balcão da cidadania, a Secretaria de Direitos Humanos, o Programa de Proteção a Crianças e Adolescentes Ameaçados de Morte (PPCAM), o Programa Municipal de Proteção à Vida (PPVida) ou o Programa ATITUDE, do governo de Pernambuco, que intervém junto a usuários de drogas que estão em situação de risco de vida.

Segundo o Ministério da Saúde (BRASIL, 2010), os encaminhamentos podem ser tanto para os profissionais da equipe como externos, para os serviços da rede de saúde e/ou assistência social. Esse último é denominado interinstitucional, podendo acontecer para recursos comunitários (escolas, centros culturais ou esportivos) ou para equipamentos de saúde como PSF, UBS, CAPS, entre outros. O profissional que realiza esse encaminhamento fica responsável pelos desdobramentos, respeitando o vínculo que foi estabelecido inicialmente. Dessa forma pretende-se potencializar as ações do CR, sensibilizando os profissionais dos outros serviços.

Além das açóes citadas anteriormente, os profissionais mencionaram a realização de visitas domiciliares, que podem ter a finalidade de monitorar os pacientes que foram encaminhados para tratamento no CAPSad, para saber sua situação atual e também para buscar familiares que ainda possuam vínculo com o usuário em questão.

De acordo com o Ministério da Saúde (BRASIL, 2010), a visita domiciliar surge como uma forma de mobilizar os familiares dos usuários e também é mais uma maneira de favorecer o acesso da população em situação de rua aos dispositivos de saúde (JORGE; CORRADI-WEBSTER, 2012).

Dois entrevistados citaram também a realização de açóes pontuais, em festas do município e datas comemorativas, e o planejamento de açóes em eventos de grande porte, como a Copa do Mundo e a das Confederaçóes.

\subsection{Dificuldades da eCR}

Outra questão discutida com os profissionais da eCR foi com relaçáo às dificuldades que podem surgir no cotidiano desse serviço relacionadas à rede de atendimento, às características da abordagem e do público atendido e à estruturação do serviço.
Em relação à rede de atendimento, foi relatada a ausência de uma rede consolidada durante a noite, período em que muitas ações são realizadas pelo CR. Destacou-se também a dificuldade de acesso do usuário em situação de rua aos serviços de saúde devido a "barreiras burocráticas" principalmente relacionadas à exigência de documentação (identificação, comprovação de endereço) dos usuários para que sejam atendidos.

Uma coisa que a gente tem na rua que a gente acha uma dificuldade é que pessoas em situação de rua, pra fazer o cartãozinho SUS, que precisa pra ir pra rede de saúde, ele precisa da identidade, mas pra tirar a identidade precisa de certidão, né, do registro de nascimento (Sarará).

Aspectos semelhantes foram apontados por Santana (2010) em relação à intervenção junto a crianças e adolescentes em situação de rua. Essas dificuldades estáo relacionadas à ausência de documentos exigidos para o acesso à rede e ao preconceito que eles sofrem, o que culmina no náo reconhecimento de seus direitos, reforçando a exclusão social e surgindo como barreira para o cuidado humanizado (JORGE; CORRADI-WEBSTER, 2012; SANTANA, 2010).

A população em situação de rua tem a marca da invisibilidade social, decorrente ao preconceito que essas pessoas sofrem, sendo muitas vezes nomeadas "moradores de rua" quando esses não constituem sequer um grupo social propriamente dito. A exclusão social é percebida também na dificuldade de acesso a saúde, moradia, educação e trabalho, sendo reflexo do modo como a sociedade reconhece essas pessoas. Contudo, são apenas pessoas de idades e origens variadas que fazem da rua o seu lugar de moradia (NERY FILHO; VALÉRIO; MONTEIRO, 2011).

Diante desse público específico, com demandas por vezes complexas, congruente com o que apontam os entrevistados, o MS (BRASIL, 2010) vê o CR como um equipamento que pode promover articulação na rede intersetorial por meio de encaminhamentos, construindo práticas que possibilitam atender as necessidades da população. Essa articulação intersetorial é vista também como um desafio complexo e permanente (JORGE; CORRADIWEBSTER, 2012).

Além das dificuldades na articulação da rede, os profissionais também relataram problemas inerentes às próprias características das açôes que são realizadas pelo CR e do público atendido por ele. Nesse sentido, um dos pontos destacados refere-se às dificuldades em relação a alguns instrumentos de intervenção utilizados (berimbau e pandeiro), que algumas 
vezes podem não ser bem aceitos por toda a equipe ou, em alguns momentos, não agradar a clientela, causando efeitos contrários ao esperado. Sendo assim, é importante que o profissional esteja atento, a fim de que pondere o uso desses instrumentos de acordo com o contexto.

Esse é o meu entendimento, assim, pode ser que algumas pessoas nem gostem e nem tenham essa possibilidade de tocar um instrumento, de ter que chegar com a palavra mesmo, mas é um treinamento bem legal (Sarará).

Por ser uma clínica de rua, o CR está sempre se adequando à dinâmica local, construindo o seu setting terapêutico, desterritorializado, com tecnologias livres e baseado no vínculo e no acolhimento à população em questão. A equipe, por isso, deve conhecer as especificidades da população que será atendida e considerar sempre as características do território e o contexto atual (NERY FILHO; VALÉRIO; MONTEIRO, 2011; BRASIL, 2010).

Ainda, sobre intercorrências durante a abordagem no CR, um profissional mencionou questôes relativas à periculosidade dos locais de visita, principalmente em decorrência do tráfico de drogas.

Então a gente faz essas visitas, fazemos observaçōes nas comunidades e havendo condiçóes, porque às vezes não há condiçôes, que o tráfico é muito, é uma área muito perigosa, mas quando há condiçôes a gente faz abordagem mesmo, corpo a corpo com eles, e temos tido êxito nisso (Marcelo).

Para a eCR de Salvador, atuar em locais perigosos é algo inerente ao equipamento, devido ao público alvo. No entanto, acredita-se que a segurança dos profissionais de saúde está diretamente relacionada ao reconhecimento da comunidade para com eles. Entende-se também que o CR é uma proposta recente, o que prejudica o reconhecimento e a aceitaçáo inicial da comunidade. Devido a esses fatores, a periculosidade do local é considerada durante o planejamento das açôes, buscando-se sempre a segurança da equipe (NERY FILHO; VALÉRIO; MONTEIRO, 2011).

A resistência e/ou desistência dos usuários ao tratamento foi citada como uma dificuldade cotidiana no serviço.

Muitas vezes eles não conseguem, assim, chegar perto de você e confessar que usam uma droga. Eles, muitas vezes, eles escondem aquilo, mas na medida que você divulga que existem instituiçōes, existem órgãos que podem cuidar deles, então você tá alertando (Alice).
Destacam-se também as dificuldades das famílias dos usuários, que podem culminar na resistência em recebê-los de volta em casa, devido a todo sofrimento já vivenciado.

Enquanto grupo primário, a família apresenta-se como o locus responsável pelos aportes afetivos e materiais necessários para o desenvolvimento das crianças e dos adolescentes. No contexto brasileiro, caracterizado pela desigualdade social, as famílias têm dificuldades em cumprir seu papel devido à situação de vulnerabilidade em que vivem, marcadas pela fome e miséria, tendo que, por vezes, aceitar que os filhos utilizem a rua como lugar de vida ou trabalho. Outro motivo para que a pessoa viva em situação de rua é o envolvimento com álcool e/ou outras drogas, o que provoca medo e recusa de seu retorno para casa por parte dos familiares (BOTTI et al., 2010; GONTIJO; MEDEIROS, 2009).

Outro grupo de dificuldades citadas pelos participantes do estudo refere-se à estruturação do serviço. Nesse âmbito, um ponto destacado pela maioria dos profissionais refere-se aos poucos investimentos realizados pelos gestores e autoridades no CR.

Seria o investimento, o governo investir mais nesses profissionais, investir mais nesse tipo de, nesses pacientes, nesses usuários, investir mais, entendeu? Fazer mais contratação de profissionais competentes (Alice).

Além disso, a falta de materiais (educativos e de consumo) suficientes para as açóes da eCR compromete a execução das açôes. Segundo os profissionais, esses materiais são necessários para que se preste um bom serviço e, muitas vezes, são adquiridos somente de maneira informal, com contatos com profissionais de outros setores e por meio da permuta do material com municípios da Região Metropolitana do Recife, PE.

Hoje a gente não tem dificuldades, mas é o que eu digo, não tem porque eu conheço (nome), do $C T A$, ai ela me manda camisinha, ai eu preciso de gel lubrificante, ai tenho (nome), do Recife, $P E$, ai gente faz permuta, ele me arruma. Eu preciso de algo que Olinda tem, Olinda passa pra mim, mas até quando isso vai acontecer, né? A gente tem que deixar isso muito claro. Pra ir começando a dar certo, mas não éo ideal. O real é esse, mas não é ideal (Magia).

A reduzida quantidade de profissionais na atual eCR também foi apontada como uma das dificuldades. Essa é justificada tanto pelo momento político do município, que na época da coleta de 
dados estava em mudança de gestáo, quanto pela falta de estímulo para os profissionais, que provoca o desgaste e o cansaço deles, levando-os a desistir ou, como outro profissional refere, "migrar" para outro serviço. Além do número de profissionais na equipe, o fato de o município contar somente com uma eCR foi também apontado como uma dificuldade, não sendo suficiente devido a extensão do município, que se divide em muitas regionais, cada uma com as suas peculiaridades.

Em relação às equipes, sugeriu-se a transformação do CR para Consultório na Rua (conforme relatada anteriormente) como uma possível solução para lidar com essas dificuldades.

A necessidade dessa transformação do Consultório de Rua pro Consultório na Rua, porque a gente mantém a verba estadual e ela é acrescida da verba nacional, no caso do Plano do Crack. Porque ai a gente garante a equipe, né, que são três modalidades (Magia).

A dificuldade dos profissionais, devido à ausência de formação prévia para a atuação no serviço, também foi citada. Uma participante relata que, durante sua formação, não houve incentivo ao estudo dessa área de intervenção, sendo que somente após ter sido contratada buscou capacitação e o aprendizado na prática do serviço.

Referiu-se também que muitos profissionais, por atuarem na área sem estarem capacitados, podem apresentar comportamentos discriminatórios em relação à clientela.

\section{[...] quando se encontra com um paciente desse muitas vezes não vai encontrar ele cheiroso, não vai encontrar ele bem vestido, de banho tomado, ai não quer chegar perto dele, existe discriminação (Alice).}

A eCR de Maceió, em concordância com a da Região Metropolitana do Recife, PE, também refere dificuldade relativa à quantidade de profissionais, devido à abrangência e complexidade das açóes realizadas pelo CR. Segundo a Portaria n. 1.190/09, a qualificação da rede está diretamente relacionada à capacitação e fortalecimento dos processos de formação permanente do pessoal, bem como ao estímulo para a contratação (JORGE; CORRADIWEBSTER; 2012; BRASIL, 2010).

Além disso, como forma de orientação aos profissionais é necessário que haja constantes capacitaçóes e formaçóes, devendo essas ocorrer pela ação integrada de gestores estaduais e municipais de saúde, permitindo que profissionais que não sejam da área de álcool e outras drogas adquiram informaçóes sobre essa temática, o que facilitaria a sua participação como componente da rede de saúde em casos de encaminhamento. A capacitação também tem o objetivo de renovação para os profissionais que lidam diariamente com essa clientela (BRASIL, 2004, 2010).

\section{Considerações finais}

Os dados provenientes dessa pesquisa permitem que se avalie uma dimensão dos desafios enfrentados por esse grupo de profissionais na execução das intervençóes junto aos usuários de drogas.

Durante a realização da pesquisa notou-se que os profissionais refletiram sobre as ações desenvolvidas na equipe bem como sobre fatores que dificultam a prática do CR do município.

Percebeu-se que, consoante ao projeto inicial do $\mathrm{CR}$, vêm sendo desenvolvidas açôes de promoção e prevençáo da saúde, bem como de redução de riscos e danos sociais e à saúde de pessoas usuárias de álcool e outras drogas, cujas especificidades exigem atenção direcionada e singularizada. Reforça-se a necessidade de a eCR estar ciente dos seus objetivos, a fim de cumprir as demandas dos usuários do CR de maneira satisfatória e dentro da realidade do serviço, seja com orientações, seja com encaminhamentos interinstitucionais.

As ações realizadas pela equipe, a aproximação e a abordagem aos usuários, com suas estratégias e ferramentas utilizadas, foram descritas e são consoantes à proposta do projeto inicial do CR de Salvador.

No entanto, apesar de muitos resultados coincidirem com o que foi proposto acerca do $\mathrm{CR}$, foram referidas dificuldades no cotidiano do serviço. Essas dificuldades estão relacionadas à rede de atendimento, às características da abordagem e do público atendido e à estruturação do serviço. As questóes mais relatadas foram as barreiras burocráticas, o preconceito com a clientela, a dificuldade de as famílias lidarem com essa situação e a necessidade de investimento maior no equipamento, tanto com relação à manutenção de materiais quanto à contratação e capacitação dos profissionais.

Em relaçáo ao leque de profissionais que compóem a eCR, compreende-se que o terapeuta ocupacional traz contribuiçôes que podem potencializar as açôes do CR. Nesse sentido, destacam-se a formação direcionada para a atuação nos diferentes níveis de atenção à saúde, em perspectivas sustentadas pela interdisciplinaridade, e a capacitação para a utilização 
de diferentes tipos de atividades na mediação do processo terapêutico.

$\mathrm{Na}$ medida em que o terapeuta ocupacional desenvolve sua atuação e direciona seu olhar para o desempenho ocupacional dos sujeitos, compreendendo esse desempenho como a maneira com que eles se desincumbem dos seus diversos papéis, bem como considera os fatores que interferem ou que favorecem esse desempenho, esse profissional contribui na abordagem da clientela como aqui descrita, tomando em conta as vulnerabilidades a que os clientes estão expostos na determinação de sua condição de saúde, para além da questão puramente de presença de doenças.

Considerando a implantação ainda recente desse serviço na rede de assistência à saúde para usuários de álcool e outras drogas, destaca-se a importância da capacitação e formação continuada dos profissionais acerca dessa temática, a fim de esclarecer questôes/ dúvidas específicas e permitir um novo olhar sobre essa clientela, que tem o direito de fazer parte da rede e que tem sido, por vezes, excluída. A partir do momento em que a gestão e os profissionais das redes de saúde e assistência ampliarem a visão sobre essa população e sobre o equipamento, acredita-se que serão possíveis maiores investimentos, permitindo a intensificação e ampliação das intervençôes junto a essa população, com a efetivaçáo da articulação intersetorial.

\section{Referências}

BARROS, M. M. M. A. Atuação da terapia ocupacional no Centro de Atenção Psicossocial - CAPS de Sobral - Ceará. Revista CETO, São Paulo, v. 12, n. 12, p. 62-75, 2010. Disponível em: <http://www.ceto.pro.br/revistas/12/12-11. pdf $>$. Acesso em: 20 abr. 2013.

BOTTI, N. C. L. et al. Padrão de uso de álcool entre homens adultos em situaçáo de rua de Belo Horizonte. SMAD: Revista Eletrônica Saúde Mental Álcool e Drogas, Ribeirão Preto, v. 6, p. 536-555, 2010. Disponível em: <http://www.revistas.usp.br/smad/article/ view/38731/41584>. Acesso em: 22 abr. 2013.

BRASIL. Portaria no 2.197, de 14 de outubro de 2004. Redefine e amplia a atençáo integral para usuários de álcool e outras drogas, no âmbito do Sistema Único de Saúde - SUS, e dá outras providências. Diário Oficial da República Federativa do Brasil, Poder Executivo, Brasília, DF, 2004. Disponível em: <http://www.sesa.pr.gov.br/ arquivos/File/20042010.pdf>. Acesso em: 14 maio 2012.

BRASIL. Ministério da Saúde. Coordenação Nacional de Saúde Mental. Consultórios de Rua do SUS. Material de trabalho para a II Oficina Nacional de Consultórios de Rua do SUS. Brasília, 2010. Disponível em: < http://portal. saude.gov.br/portal/arquivos/pdf/consult_rua17_1_11. pdf $>$. Acesso em: 30 mar. 2013.
BRASIL. Portaria no 2.488, de 21 de outubro de 2011. Aprova a Política Nacional de Atenção Básica. Diário Oficial da República Federativa do Brasil, Poder Executivo, Brasília, DF, 2011. Disponível em: <http://www.brasilsus. com.br/legislacoes/gm/110154-2488.html>. Acesso em: 4 abr. 2013.

BRASIL. Portaria no 122 , de 25 de janeiro de 2012. Define as diretrizes de organização e funcionamento das equipes de Consultório na Rua. Diário Oficial da República Federativa do Brasil, Poder Executivo, Brasília, DF, 2012a. Disponível em: <http://www.sesa.pr.gov.br/ arquivos/File/Portaria_122_Consultorio_na_Rua.pdf $>$. Acesso em: 4 abr. 2013.

BRASIL. Portaria no 123 , de 25 de janeiro de 2012. Define os critérios de cálculos do número máximo de equipes de Consultório na Rua (eCR) por Município. Diário Oficial da República Federativa do Brasil, Poder Executivo, Brasília, DF, 2012b. Disponível em: <http://bvsms.saude.gov.br/ bvs/saudelegis/gm/2012/prt0123_25_01_2012.html>. Acesso em: 4 abr. 2013.

BRASIL. Ministério da Saúde. Cadastro Nacional de Estabelecimentos de Saúde. DATASUS. Consultas: equipes. Brasília, 2013. Disponível em: <http://cnes.datasus.gov. br/Mod_Ind_Equipes.asp >. Acesso em: 1 abr. 2013.

COUTINHO, D.; SABACK, E. O histórico da Psiquiatria na Bahia. Gazeta Médica da Bahia, Bahia, v. 77, n. 2, p. 210-218, 2007. Disponível em: <http://www.gmbahia. ufba.br/ojs/index.php/gmbahia/article/viewFile/102/95>. Acesso em: 17 maio 2012.

GOMES, R. Análise e interpretação de dados de pesquisa qualitativa. In: MINAYO, M. C. S. (Org.) Pesquisa social: teoria, método e criatividade. Rio de Janeiro: Vozes, 2008. p. 79-108. PMid:18854599.

GONÇALVES, P. R. A.; BRAITENBACH, D. P. F. O CR Interdisciplinar: olhares mpliados. In: NERY FILHO, A.; VALÉRIO, A. L. R. (Orgs.). Módulo para capacitaçâo dos profissionais do projeto CR. Brasília: Secretaria Nacional de Políticas sobre Drogas, 2010. p. 43-48. Disponível em: <http://www.obid.senad.gov.br/portais/OBID/ biblioteca/documentos/Capacitacao/328365.pdf>. Acesso em: 13 maio 2012.

GONTIJO, D. T.; MEDEIROS, M. Crianças e adolescentes em situação de rua: contribuiçôes para a compreensão dos processos de vulnerabilidade e desfiliação social. Ciência \& Saúde Coletiva, Rio de Janeiro, v. 14, n. 2, p. 467-475, 2009.

JORGE, J. S.; CORRADI-WEBSTER, C. M. CR: contribuições e desafios de uma prática em construção. Saúde \& Transformação Social, Florianópolis, v. 3, n. 1, p. 39-48, 2012.

INTERNATIONAL HARM REDUCTION ASSOCIATION - IHRA. O que é redução de danos? London, 2010. Disponível em: <http://www.ihra.net/ files/2010/06/01/Briefing_what_is_HR_Portuguese. pdf>. Acesso em: 9 fev. 2014.

MINAYO, M. C. S. Pesquisa social: teoria, método e criatividade. Rio de Janeiro: Vozes, 2008. 
MORAIS, N. A. et al. Promoção de saúde e adolescência: um exemplo de intervenção com adolescentes em situação de rua. Psicologia \& Sociedade, Belo Horizonte, v. 22, n. 3, p. 507-518, 2010.

NERY FILHO, A.; VALÉRIO, A. L. R.; MONTEIRO, L. F. (Orgs.). Guia do Projeto Consultório de Rua. Brasília: SENAD; Salvador: CETAD, 2011. Disponível em: <http://www.obid.senad.gov.br/portais/OBID/biblioteca/ documentos/Publicacoes/cartilhas/329225.pdf>. Acesso em: 1 abr. 2013.

OLIVEIRA, L. G.; NAPPO, S. A. Caracterização da cultura de crack na cidade de São Paulo: padrão de uso controlado. Revista de Saúde Pública, São Paulo, v. 42, n. 4, p. 664-671, 2008. http://dx.doi.org/10.1590/ S0034-89102008005000039

PERNAMBUCO (Estado). Secretaria Estadual de Saúde - SES. Programas e açóes. Pernambuco, 2012. Disponível em: <http://portal.saude.pe.gov.br/programase-acoes/dasdasd/saude-mental/>. Acesso em: 16 maio 2012.

SANTOS, A. M.; MALHEIRO, L. Redução de danos: uma estratégia construída para além dos muros institucionais.
In: NERY FILHO, A.; VALÉRIO, A. L. R. (Orgs.). Módulo para capacitação dos profissionais do projeto CR. Brasília: Secretaria Nacional de Políticas sobre Drogas, 2010. p. 49-53. Disponível em: < http://www.obid.senad.gov.br/ portais/OBID/biblioteca/documentos/Capacitacao/328365. pdf>. Acesso em: 13 mai. 2012.

SANTANA, J. P. A intervenção com crianças e adolescentes em situação de rua: possibilidades e desafios. In: NERY FILHO, A.; VALÉRIO, A. L. R. (Orgs.). Módulo para capacitação dos profissionais do projeto CR. Brasília: Secretaria Nacional de Políticas sobre Drogas, 2010. p. 25-33. Disponível em: <http://www.obid.senad.gov.br/ portais/OBID/biblioteca/documentos/Capacitacao/328365. pdf >. Acesso em: 13 maio 2012.

VALÉRIO, A. L. R.; MENEZES, A. C. C. A Rede de atenção ao usuário de spa em contexto de rua. In: NERY FILHO, A.; VALÉRIO, A. L. R. (Orgs.). Módulo para capacitação dos profissionais do projeto CR. Brasília: SENAD, 2010. p. 54-60. Disponível em: < http://www. obid.senad.gov.br/portais/OBID/biblioteca/documentos/ Capacitacao/328365.pdf>. Acesso em: 13 maio 2012.

\section{Contribuição dos Autores}

Viviane Cássia Aranda de Souza: Responsável pela redação do projeto de pesquisa, coleta e análise dos dados; realizou a redaçáo do manuscrito. Andrea Ruzzi Pereira: Colaborou nas análises, redação final e revisáo do manuscrito. Daniela Tavares Gontijo: Orientou o desenvolvimento do projeto de pesquisa (incluindo coleta e análise de dados) e a redaçáo do artigo, assim como realizou a revisão do manuscrito.

\section{Notas}

${ }^{1}$ Pesquisa resultante do trabalho de conclusão de curso em Terapia Ocupacional da Universidade Federal de Pernambuco (UFPE) - aprovada pelo Comitê de Ética em Pesquisa em Seres Humanos do Centro de Ciências da Saúde (CCS) da UFPE de acordo com o protocolo 165.133 . 